\title{
casa wiley
}

PHILIP JOHNSON y asociados, arquitectos

El éxito de la casa Wiley consiste, principalmente, en el fruto conseguido por el esfuerzo de sus proyectistas en lograr la diferenciación de funciones que se realizan en toda vida familiar. Con ello, se ha logrado armonizar dos elementos tal vez incompatibles: la pureza de la arquitectura moderna y las necesidades de toda vida en familia. ¿Por qué la gente no puede aprender a vivir en los espacios sin ventanas de Ledoux, ni en los prismas de cristal de Mies van der Rohe?

Sencillamente, porque la gente necesita una zona para que la niña de la casa toque el piano mientras su mamá juega al bridge con sus amigas; necesita una casa, en la que se puedan desarrollar simultáneamente las actividades más diversas y en la que cada individuo de la familia tenga su lugar íntimo de recogimiento para el descanso o trabajo.

¿Y qué forma puede producir el artista para poder satisfacer a todas estas necesidades especiales?... Una respuesta podría ser el espacio compartimentado de las casas del siglo XIX: habitaciones de dormir, de estar, de comer, de jugar al billar, de tomar el desayuno, de recibir visitas... Hoy, desgraciadamente, esto ni satisface a nuestras formas de vida, ni es posible de realizar.

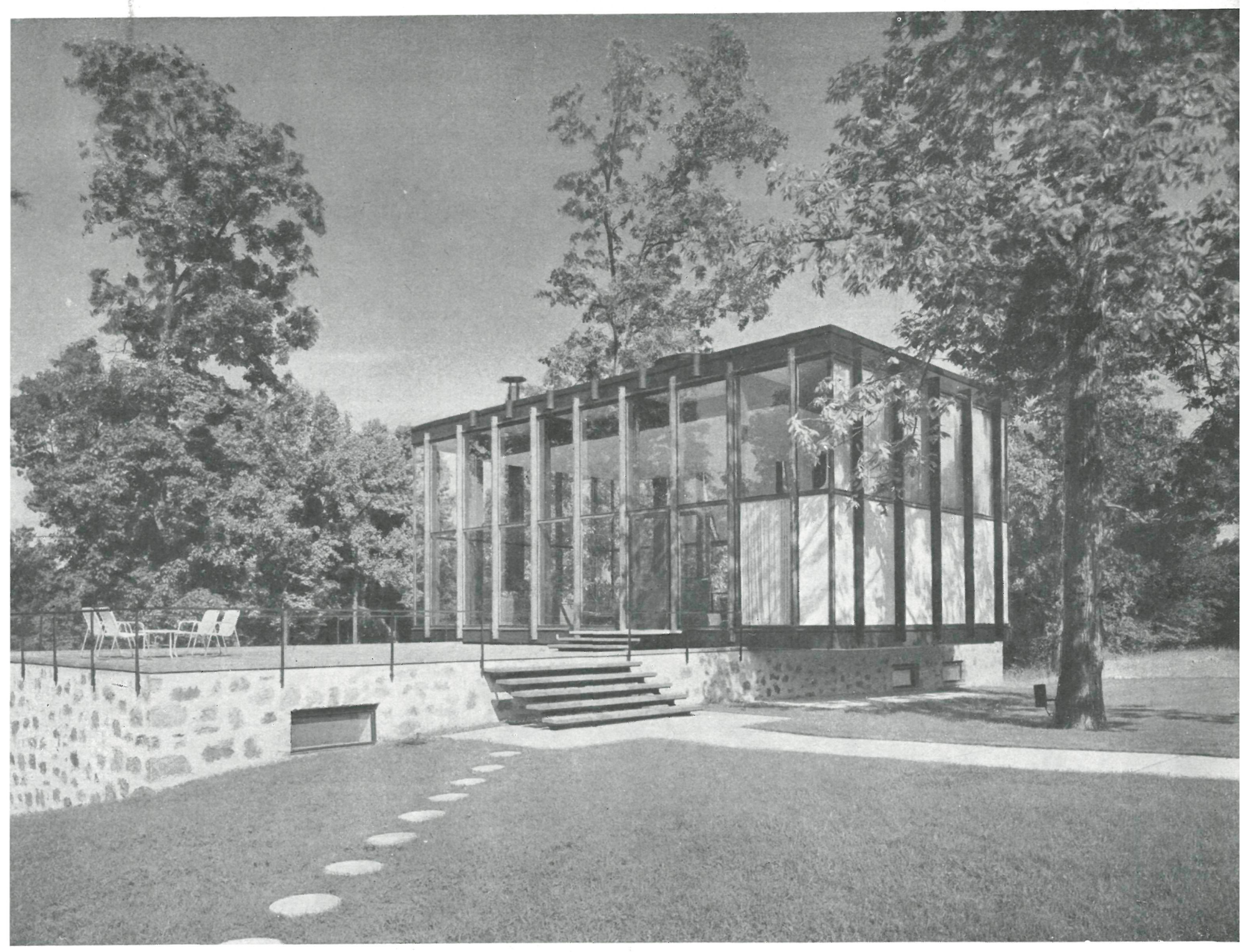

$161-75$ 

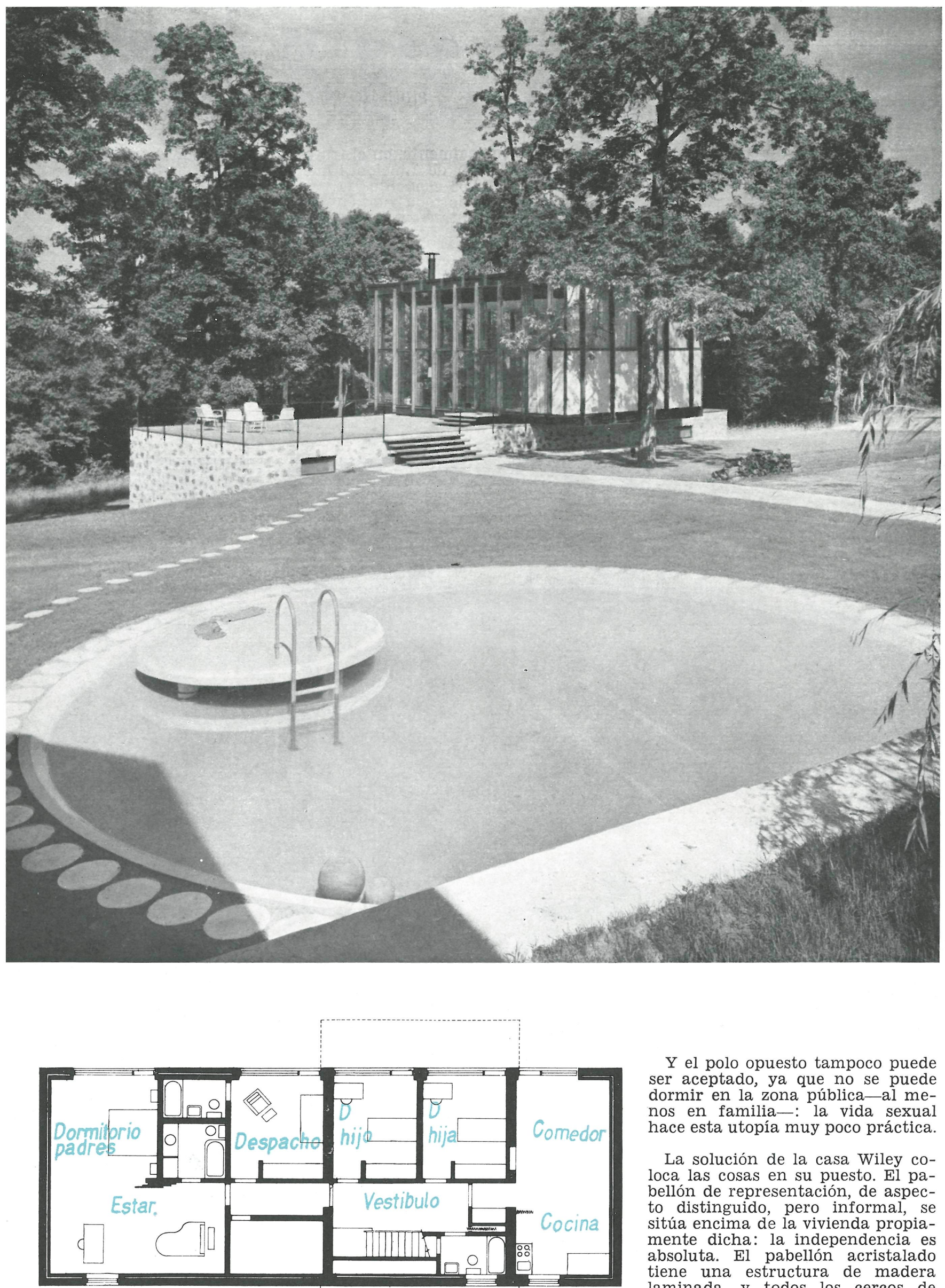

$Y$ el polo opuesto tampoco puede ser aceptado, ya que no se puede dormir en la zona pública-al menos en familia-: la vida sexual hace esta utopía muy poco práctica.

La solución de la casa Wiley coloca las cosas en su puesto. El pabellón de representación, de aspecto distinguido, pero informal, se sitúa encima de la vivienda propiamente dicha: la independencia es absoluta. El pabellón acristalado tiene una estructura de madera laminada, y todos los cercos de ventana son también de madera más oscura. 

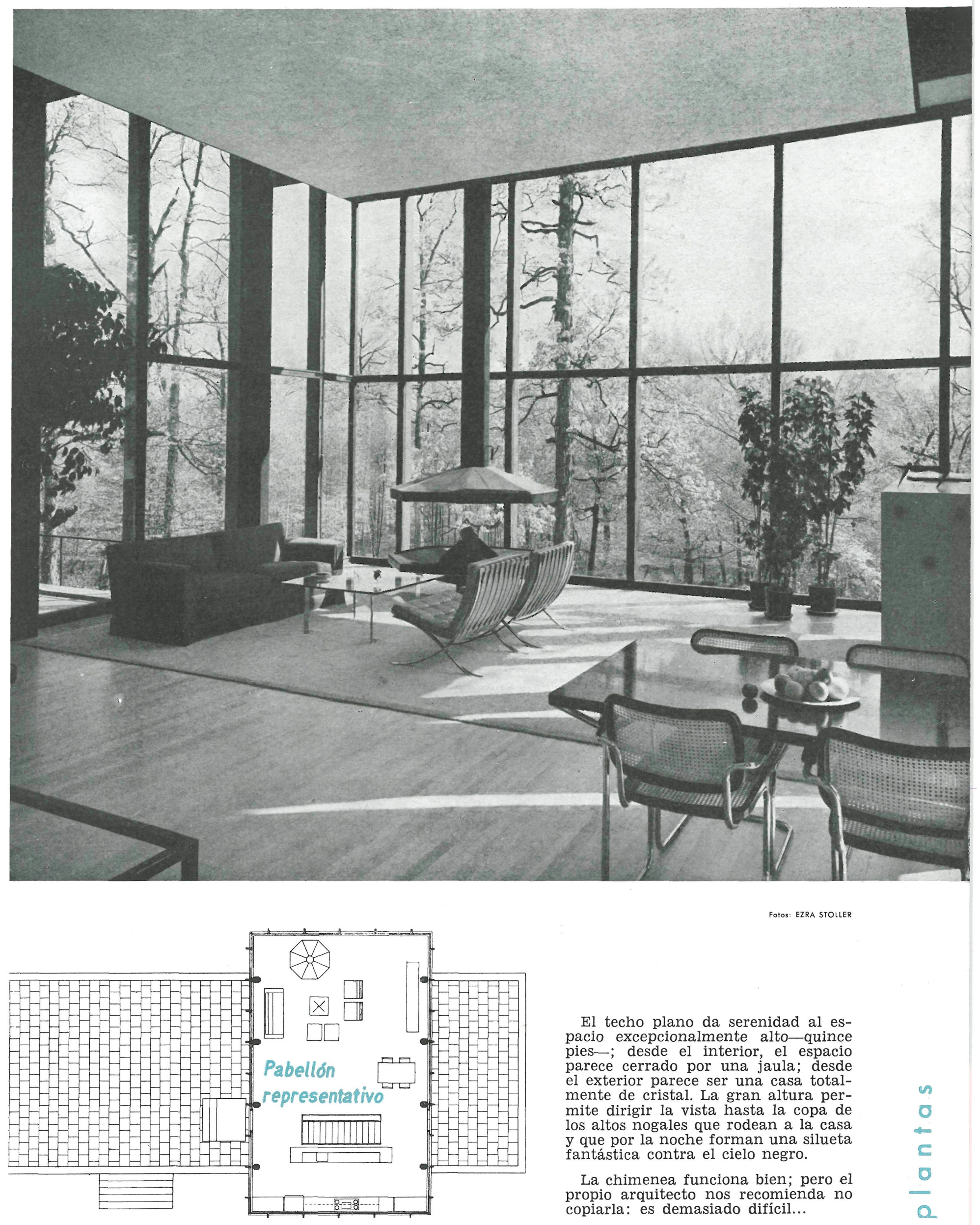

Fotos: EZRA STOLLER

El techo plano da serenidad al espacio excepcionalmente alto-quince pies-; desde el interior, el espacio parece cerrado por una jaula; desde el exterior parece ser una casa totalmente de cristal. La gran altura permite dirigir la vista hasta la copa de los altos nogales que rodean a la casa y que por la noche forman una silueta fantástica contra el cielo negro.

La chimenea funciona bien; pero el propio arquitecto nos recomienda no copiarla: es demasiado difícil... 